\title{
Reasoning in a multicultural society
}

\author{
DONNY GAHRAL ADIAN
}

\begin{abstract}
Multicultural society as a way of being-with-others needs a certain form of public reasoning. Unfortunately, the current yet dominant form of public reasoning is infiltrated by biases from occidental culture. This mode of reasoning does nothing but uproot participants from their cultural identity for the sake of universal consensus. Multicultural society, however, consists of identities which are embedded in the individuals' cultural tradition. This sociological fact demands a richer form of rationality that does not deny the multiplicity of cultural values and embedded identities. We need a form of public reasoning which emphasizes cultural understanding rather than abstract consensus. We might call it a multicultural, contextualized and other-regarding form of public reason.

KEYWORDS

Multiculturalism, multicultural society, culture, reason, public reason, occidental reason, communicative rationality, apodictic reason, ad hominem reason, value pluralism.
\end{abstract}

Social thinker Bhikhu Parekh argues that the last four decades of the twentieth century witnessed the emergence of a cluster of intellectual and political movements led by such diverse groups as indigenous peoples, national minorities, ethno-cultural nations, old and new immigrants, feminists, gay men and lesbians, and the greens (Parekh 2000: 1). They promote practices, life-styles, views, and ways of life that are different from, disapproved of, and in varying degrees denied by the dominant culture. Although too disparate to share a common philosophical and political agenda, they are all united in resisting the wider society's homogenizing or assimilationist thrust based on the belief that there is only one correct, true, or normal way to understand and structure life's social, cultural, and political areas.

Multiculturalism is essentially a philosophy-based political agenda that demands the recognition of the multiplicity of cultural values. Multiculturalism emphasizes the need to recognize that each culture is a community of values

DONNY GAHRAL ADIAN is researcher in Political and Social Philosophy, Philosophy Department, Faculty of Humanities, University of Indonesia. His publications include Demokrasi kami (2007), Demokrasi substansial: Risalah kebangkrutan liberalisme (2010), and Pengantar fenomenologi (2010). Donny Gahral Adian may be contacted at religiana@yahoo.co.uk.

(C) 2011 Faculty of Humanities, University of Indonesia 
with its own way of thinking and being. The key objective of multiculturalism is political and societal sustainability. This objective, however, cannot be easily achieved as some commitments to values are so fundamental that they curtail the probability of consensus. For some thinkers of modernity, this issue is quite intriguing since the dream of modernity cannot be negotiated with politics of identity. Modernity insists that the public realm must be secured from sectarian values and governed by nothing but public values all citizens consent to.

Modern thinker Jurgen Habermas, proposes some kind of idealized form of rationality to warrant the possibility of consensus in the public sphere, namely communicative rationality. His communicative rationality, however, is severely criticized by many thinkers who have abandoned the universal dream of modernity. I would contend that Habermas' proposed rationality itself is rooted in post-Renaissance European intellectual culture that involves a particular mode of truth, reason, and reality. Habermas' communicative rationality is, in fact, an occidental rationality that uproots individuals from their cultural identity. Multiculturalism needs a richer form of rationality that, unlike Habermas' rationality, accepts the multiplicity of cultural values in the name of pseudo universality. This article tries to uncover the hidden assumption behind Habermas' communicative rationality in order to propose a new mode of rationality that is more commensurate with multiculturalism. First, I will try to reformulate multiculturalism as value pluralism that most likely denies reasoned consensus. Second, I will elaborate further how Habermas' communicative rationality is in fact the embodiment of postRenaissance European Western cultural values. Third, I will theoretically pursue new forms of relationships between rationality and identity in a multicultural society.

\section{MULTICULTURALISM AND VALUE PLURALISM}

The enemies of multiculturalism include singularity, essentialism, and universalism. Multiculturalism is a philosophy of radical difference. As a philosophy of radical difference, multiculturalism denies the universal commensurability of cultures or values in the name of universal humanity. One of multiculturalism's basic tenets is anti essentialism. Culture is not a substance. It is not what poet Matthew Arnold says about "the best which has been thought and said in the world", a "study of perfection, harmonious and general" (Mulhern, 2000: xvi). Culture is more about what philosopher Herder has in mind about human groups' symbolic forms of life, shaped in diverse conditions and growing into new shapes as these forms encounter new demands and opportunities (Mulhern 2000: xvi).

As a philosophy of radical difference, multiculturalism can be paralleled with value pluralism. Multiculturalism as a philosophy claims that there are multiplicities of incommensurable values. In order to understand value pluralism we have to differentiate it from ethical pluralism. Ethical pluralism is a thesis that argues that there is no such thing as a single ethical standard to 
which all principles of conduct must conform. According to ethical pluralism, a number of ethical principles are equally fundamental. Value pluralism intends to go beyond that. Originating in Isaiah Berlin's philosophy, it is a thesis that claims that fundamental human values are irreducibly plural and incommensurable (Crowder 2002: 2). In other words, values can be in conflict, and there is no rationally determinable answer to the question which values should take precedence. Value conflict is inarbitrable. For instance, the value of utility can be inarbitrably in conflict with the values of care, liberty, or impartiality. There is no way we can appeal to a super-value to be able to integrate them. Berlin wrote in his major work Four Essays on Liberty (1969):

If as I believe, the ends of men are many, and not all of them are in principle compatible with each other, then the possibility of conflict-and of tragedycan never wholly be eliminated from human life, either personal or social. The necessity of choosing between absolute claims is then an inescapable characteristic of human condition. This gives value to freedom as Acton had conceived of it - as an end in itself... (Berlin 1969: 169).

Value pluralism stresses the diversity of ends of life. It is a form of antirationalism that insists that our reason is incapable to provide a single agreed-upon answer to the question, "what is the best way to live?" There are innumerable ways of living that appeal to each of us but they conflict and we are often unable to decide among them.

There are four fundamental principles of value pluralism (Crowder 2002: 2). They are universal values, pluralism, incommensurability, and conflict. I would like to elaborate on each of them further.

\section{A. Universal values}

Value pluralism holds that values are trans-historical and cross-cultural. This standpoint differs from that held by ethical relativism that claims that all values are the products of particular cultures and perspectives and possess ethical force only relative to that particular perspective. The claim of universality could be understood as values that are valuable for people's well-being or flourishing irrespective of what particular persons or cultures may believe. This is not to say, however, that these values can be identified without reference to any actual patterns of belief and practice. There are commonalities among the beliefs and practices of most human societies such that certain values, or at least the capability of realizing those values, must be seen as promoting the flourishing of any form of human life.

\section{B. Plurality}

Value pluralists believe that values, including universal values, are plural. This claim of plurality, however, must consider the types of values. There are two types of values: primary and secondary values. Primary or substantive values are universal, while secondary values vary with persons, societies, traditions, and historical periods. Nussbaum lists the substantive content of universal 
values as "central functional capabilities necessary for human flourishing" (Nussbaum 2000: 70). These capabilities are as follows:

Being able to live the end of human life of normal length; to enjoy good health, including reproductive health, adequate nourishment and shelter; to enjoy bodily integrity, including security against assault and freedom of movement; to use the senses, to imagine, think and reason; to have emotional attachments to things and people outside ones selves; to form a conception of good and to engage in critical reflection about the planning of our life; to live with and toward others, to engage in social interaction, and to have 'the social bases of self respect and non-humiliation'; to live with concern for and in relation to animals, plants and the world of nature; to laugh, play and enjoy recreational activities; to participate effectively in political choices that govern our life; and to have a real opportunity to hold property (Nussbaum 2000: 78-80).

The substantive values enlisted above are plural in the sense that they are contingent and open ended. It means that we must allow for the possibility of changes in the natural circumstances of human beings, and for the need to revise the list in order to reflect what we may yet have to learn from encounters with other human societies.

\section{Incommensurability}

Incommensurability may be understood in three ways. Values are incommensurable in the sense that they are incomparable, immeasurable, and unrankable. Values are incomparable in the sense that they are so unalike as to exclude any reasonable comparison between them. Values are immeasurable in the sense that they cannot in any precise manner be weighed or measured against one another because they cannot be represented in terms of a common denominator of measurement. Value pluralism denies the possibility of any common denominator like utility, pleasure, or highest good (sumum bonum). Values are unrankable in the sense that they cannot be put in cardinal ranking such as ranking books according to the most copies sold. We cannot rank values like we rank all other things in our daily activities.

\section{Conflict}

Values are in perpetual conflict. There are two sources of conflict. First, the ability of human beings to pursue or enjoy different values is constrained by empirical circumstances which impose limitations of various kinds and degrees. Our choices of values are forced upon us by circumstances that are, at least contemporarily, unchangeable. Second, some conflicts arise from the very nature of the values concerned. For instance, a life of independent, unencumbered self-reliance necessarily excludes a life dedicated to a large family and marital intimacy. This standpoint, of course, derives from a strong liberal position which values individualism above any other form of collective commitment. 
Value pluralism is an axiological fact which needs to be carefully understood. Failing to comprehend this may lead to two extremes. One is totalitarianism, and the other is relativism. When one believer tries to subordinate all values under his or her value-schemata, the result is totalitarianism. Isaiah Berlin traces the roots of totalitarianism to "a condition in which all values, desires, interests, and ultimately all persons are subordinated to a single overriding goal, either secular or religious" (Crowder 2000: 98). Fundamentalists have this kind of ideology in their minds. They use an instrumental type of reasoning to impose their faith-based-value-schemata as the only official one regardless of how heterogeneous existing faiths are. The value-schemata that they hold remain unexamined and never enter into enriching dialogues with others.

The other extreme is relativism. Value pluralism may lead to anti-reason relativism. It means that values can never be judged independently by the standards of one particular belief. Every belief has its own rationality. There is no overarching rationality to measure any belief objectively. If two people disagree about a value-claim, they not only have different reasons for their claims, but also disagree about what is meant by "reason". This kind of relativism is an obstacle to communication since a relativist can never engage in communication due to their instrumental form of action. Under the heading of value pluralism any communication a relativist engages in hides what is truly real: the instrumental reason. What relativists are trying to do is to impose their value by any means necessary. Still, their value remains unexamined under the vague mask called relativism.

\section{HABERMAS AND OCCIDENTAL REASON}

I feel that some modern philosophers insist that value pluralism requires political consensus. The transition from ordinary life to political life requires consensus on ultimate values upon which society is sustained. Consensus is needed since political life is a mode of living marked by plurality of values, conceptions of the good and ideals. This consensus, however, cannot be reached by imposition or coercion but through public reasoning by means of a practical mode of rationality. It must be made through public reasoning. The public way of reasoning is through practical mode of rationality. Philosopher John Rawls uses the term "public reason" as "a form of reasoning ... appropriate to equal citizens who as a corporate body impose rules on one another backed by sanctions of state power" (Rawls 2001: 92). Public reason does not promote specific associational values or principles but a public conception of justice. The opposite of public reason is the reason appropriate to individuals and associations within society. It guides how they can be quite properly deliberate in making their personal and associational decisions. Each association has its own form of reasoning which is related to its specific aims and purposes. Public reason, however, solely concerns the conception of justice all citizens accept regardless of their cultural or ideological backgrounds.

Parallel with Rawls' political consensus, German philosopher Jurgen Habermas also tries to secure the public sphere from communitarian or 
sectarian values. In my opinion, Habermas believes that a deliberative process through public reason (which he calls communicative rationality) is guaranteed to realize the condition of "ideal speech situations" where coercion is substituted by argumentation. In such a situation, every participant can endorse a moral, scientific, or aesthetic proposition without being coerced to think otherwise. If all conditions are met, we would find generalizable interests which all those relevantly affected accept. Finding these interests demands individuals to step out of their private encapsulated fundamental values, culture, and tradition. In this case, Habermas' communicative rationality goes against all forms of sectarian or context-bound rationality, because sectarian rationality knows only its own interest and refuses to communicate, and is thus unable to find generalizable interest.

Habermas' point of departure is the same as that of most enlightenment philosophers: reason is defined by the critique of tradition and authority. As with his predecessors, Habermas tries to elucidate the nature of and conditions under which a normative kind of rationality is formed. He draws a clear line between cognitive-instrumental rationality and communicative rationality, between the capacity for a decentred perception and the manipulation of things or events and the capacity for reaching an intersubjective understanding about things or events (Habermas 1984:14). Intersubjectivity is the political capacity for democratic participants as they must justify their action or belief to other political subjects. One cannot act or think without sharing with others for justification or one cannot justify one's own action or thinking in isolation. A father who is about to send his son to school doesn't need public justification. Meanwhile, it is mandatory for a governor who is about to convert a traditional market to a Mal to seek public justification before his policy is enacted. A Governor's constituent is a political subject who demands an explanation for a Governor's policy. A father's son, however, is only a member of a family as a non-political institution. For me, communicative rationality ensures that communication can become a practical discourse which is ultimately a form of argumentation seeking consensual agreement. In this way, Habermas becomes a hard-headed proponent of a modern practical rationality that endorses the human capability to reflect on the consensual norm inherent in social action.

Modern practical rationality belongs to the post-Renaissance European rationalistic tradition. Self-criticism is one of the most important features of this tradition. From Socrates to David Hume, philosophers subject all beliefs, claims, prejudices, and assumptions to the most rigorous scrutiny through the instruments of rationality, logic, and evidence. American philosopher John Searle lays down the five basic tenets of Western rationality tradition. ${ }^{1}$ Searle's first tenet is realism. Realism is the notion that there is a world "out there" that is totally free from our linguistic representations in the form of beliefs, experiences, statements, and theories. We are often so entrapped within our own representation (culture) that we cannot differentiate between representation and reality. Realism claims that we must use our reason to go 
beyond mere representation to find the world as it is.

The second tenet is correspondence. It claims that our statement or proposition must describe reality accurately. We adjudicate our propositions by measuring them against external reality. So, for example, the statement that hydrogen atoms have one electron, or that the earth is 93 million miles away from the sun is either true or false depending on whether or not things in the hydrogen atoms or solar system are really the way these statements say they are. In principle, a statement is true if, and only if, the statement corresponds to the facts.

The third is objectivity. Our knowledge does not depend on or derives from the subjective attitudes and feelings of particular investigators. The objective truth or falsity of a claim made is totally independent of the motives, morality, gender, race, and ethnicity of the maker of that claim. The principle of objectivity denies the significance of culture in the process of knowledge creation.

Formalism is the fourth tenet. According to the Western conception, rationality provides one with a set of procedures, methods, standards, and canons that enables one to assess various claims in light of competing claims. Central to this view is the Western conception of logic. Logic does not tell us what to believe. It only tells us what must be the case given that our assumptions are true, and hence what we are committed to believing given that we believe in those assumptions.

The last tenet is anti constructivism. Intellectual standards are not culturally or socially constructed. They are either objective or intersubjective. These standards are objective in the sense that they are independent of the sensibilities of the people who apply the criteria and intersubjective in the sense that they are dependent.

These tenets are interconnected. Knowledge is typically of a mind independent of reality. It is expressed in public language; it contains true propositions - these propositions are true because they accurately represent that reality - and knowledge is arrived at by applying, and is subject to, constraints of rationality and logic. The merits and demerits of theories are largely a matter of meeting or failing to meet the criteria implicit in this conception. This ideal, however, is now under attack. European philosophers such as Michel Foucault, Jacques Derrida, Thomas Kuhn, and Paul Feyerabend question some Western rationalistic tradition's claims such as universality, objectivity, and disinterestedness. In a pamphlet authored by six heads of prominent humanities institutes and issued by the American Council of Learned Societies, we read: "As the most powerful modern philosophies and theories have been demonstrating, claims of disinterest, objectivity and universality are not to be trusted and they tend to reflect local historical conditions." 2

Sociologist Gerard Delanty argues about the difficulties of Habermas' communicative rationality. He believes that Habermas' form of rationality

$2 \quad$ See Levine et al. (1989: 18). 
rests upon a particular cultural model namely occidental culture. ${ }^{3}$ Occidental culture itself is an expression of the universal features of civilized man. It is also a cultural norm to say that culture must not entrap or constrain individuals from thinking freely. Habermas' communicative rationality shares occidental culture's basic tenets. For instance, communicative rationality ensures that an individual can overcome his or her cultural constraints for the sake of public consensus. For Habermas, rationality is simply a universal procedure to settle sectarian disputes or conflicts. Guided by principles of rationality one will relativize one's own way of life with regard to the legitimate claims of other forms of life. In this way, rationality does nothing but uproot individuals from their cultural tradition.

The public sphere is unavoidably loaded with a multiplicity of cultural values. Habermas, however, emphasizes that cultural values do not yet in any way imply a claim that they would meet general assent within a culture, not to mention universal assent. Assent must be won by adopting a reflective attitude to our cultural values by making them intelligible to others by the force of reason. Habermas' communicative rationality stresses that all norms should be able to be adjudicated rationally in the public sphere, which is neutral and anchored in the following assumptions:

(a) Every subject with the competence to speak and act is allowed to take part in a discourse.

(b) Everyone is allowed to question any assertion whatever.

(c) Everyone is allowed to introduce any assertion whatever into the discourse.

(d) Everyone is allowed to express his attitudes, desires and needs.

(e) No speaker may be prevented by internal or external coercion, from exercising his or her rights as laid down above.

(Habermas 1999: 89).

All cultural values, according to Habermas, must be moulded to meet the requirements above. The problem is that all these requirements are based on a certain cultural model which is occidental culture. This being so, it results in the imposition of a single cultural standard on the multiplicity of cultural values. The occidental cultural standards are impartiality, equal treatment, protection of fundamental rights, and self-criticism or reflectivity. These standards, however, cannot answer problems like cultural survival in a multicultural society. In Canada, for instance, Quebec's Francophones or Quebeckers reacted against the Canadian Charter of Rights, which, while it defines a set of individual rights guaranteeing equal treatment regardless of race, sex, or other grounds, the Quebeckers maintain that the survival of their culture requires certain restrictions on precisely these rights. For example, French-speaking citizens are not allowed to send their children to Englishlanguage schools, businesses of more than fifty employees should be run in French, and no commercial signs are to be written in English.

These rules, however, may be perceived as discriminatory. Why should

$3 \quad$ See Delanty 1997. 
Francophones not be allowed to send their children to any schools they want provided they can afford it? Different from what Habermas has in mind, Quebeckers assume that the survival and flourishing of French culture in Quebec transcends rational adjudication. French culture is not to be scrutinized rationally but recognized as a legitimate demand for radical difference. Quebec's French culture cannot be measured by occidental standards of impartiality, objectivity, and reflectivity. It demands, however, that these unrecognized standards be moulded to allow for the values of particular cultures and conceptions of the good. It demands not some occidental-driven rationality but a rationality that regards other culture as an important starting point for a mutually enriching dialog.

\section{RATIONALITY AND IDENTITY}

Should reason uproot someone from their cultural identity? This becomes problematic since uprooting someone from his or her cultural identity is diametrically opposed to the multicultural condition of society. How then should we reason in multicultural society? One thing for sure, we should reason in a way that does not abstract ourselves and others from cultural values or traditions. We must, therefore, propose new forms of affiliation between rationality and identity; an affiliation which is more appropriate to multicultural society.

We might learn from Charles Taylor's differentiation between apodictic and ad hominem rationality (Taylor 1995: 36). Apodictic rationality is a way of reasoning which is based on a fundamental commitment to certain principles. This rationality constantly proposes criteria to make a decision among several contesting claims. Apodictic rationality decides upon an action to take based on external measurements (Taylor 1995:37). For example, based on the apodictic rationality, $\mathrm{Y}$ is better than $\mathrm{X}$ because $\mathrm{Y}$ is supported by more accountable field data. Apodictic rationality is a transitional rationality, that is a rationality that guides us to shift from one choice $(X)$ to another $(Y)$ based on a certain criterion or principle. Based on this idea, Habermas' communicative rationality is apodictic because it decides upon contesting cultural claims based on fundamental commitment to occidental culture.

The second concept of rationality proposed by Charles Taylor proposes another concept of rationality, which is what he calls ad hominem rationality (Taylor 1995: 38). Different from apodictic rationality, ad hominem rationality is not based upon the fundamental commitment to a certain principle but departs from what becomes other people's commitment, identity, or perspective. Instead of becoming an object of criticism based on a certain principle, other people's commitment becomes the point of departure for a mutually enriching conversation. Note the following illustration:

Someone used to refuse to greet his neighbour due to a religious difference. He did that based on his belief that befriending an infidel would lead him to religious deterioration. However, one day he could not avoid talking with the neighbour. From the conversation, he concluded that the neighbour was 
a compassionate person. He reflected on his belief and asked himself: "Will such a compassionate person bring me into religious deterioration?" Reading from Taylor's work, ad hominem rationality works by changing the agent's wishes and preferences by minimizing the mistakes, which were manifest in his conversation with the neighbour.

Here the difference is clear between ad hominem and apodictic rationalities. Apodictic rationality intends to release an agent from the confinement of his private perspective by embracing a certain objective principle. Meanwhile, ad hominem rationality departs from other people's commitment. However, the rationality of action which struggles with concrete individuals has no choice but to take other people's identity into account. As shown above, the neighbour's commitment to moderation and compassion becomes his point of departure to reflect on the fundamentalist's rigid religious commitment.

Ad hominem rationality requires an intense and concrete conversation between persons. Individuals can argue against each other to change each other's wishes and preferences. The encounter with other people as concrete individuals is a new experience which can change or enrich one's wishes and preferences. The change from one wish to another is not based on an external criterion but on an argumentation which considers other people's commitment, perspective, or identity.

Identity itself should not be regarded as a constraint to rational reflectivity. According to Korsgaard, a normative question will not be asked by some impartial spectator but by someone who is troubled by such question. She argues:

The normative question is a first person question that arises for the moral agent who must actually do what morality says. When you want to know what a philosopher's theory of normativity is, you must place yourself in the position of agent on whom morality is making a difficult claim. You then ask the philosopher: must I really do this? Why must I do it? And his answer is his answer to the normative question (Korsgaard 1996: 16).

The answer to a normative question has to enable us to greet someone in his or her position as a first person. An agent considers whether he or she has to do something reasonable rationally or not. Moreover, the answer has to concern our identity-ness. An example is the moral decision to donate to charity. This decision is based not just on the principle of distributive justice which is general in nature but is instilled in the identity of the charity giver as a devout Muslim.

I have some problems with Korsgaard's standpoint. First, do I give alms just because of my practical identity as a Muslim? If so, the moral imperative to give alms becomes simply a conditional one. Secondly, how do I reconcile between a general characteristic of a principle of action with the particularity of practical identity? How does someone in his particularity support a general principle of action?

Korsgaard mentions that practical identity has inherently two meanings. 
First of all, one's practical identity can be understood as the condition of one's particular identity. Second, practical identity is a general character which is inherent in one's humanity. The authority of rationality in dictating an action, argues Korsgaard, shifts from being based on practical identity as a particular psychological fact to practical identity as a general character of agency which invites public's commitment to action (Korsgaard 1996: 121) .

Korsgaard declares that if reflectivity is a source of rationality, practical identity is a source of obligation (Korsgaard 1996: 102). Both are interconnected. Reading from Korsgaard work, a rational reason for action is not simply an abstract rule. A rational reason is an expression which represents one's value and character. Practical identity is "a description by which one values herself, a description by which one finds that her life is worth living and her actions are worth doing" (Korsgaard 1996: 101).

Self-conception is possible due to reflective capacity which engenders rational reasons. We feel that we have obligations because we have a personal identity through which certain actions seem forbidden. A devout Muslim may think: "I cannot bear the embarrassment if I do not donate to charity." One's practical identity as a Muslim makes the action of "not giving charity" to have become forbidden and to contradict one's self-conception as a Muslim. Basing myself on Korsgaard's work, for me, our rational reason has a normative power because of two things. First, we attach authority to that reason through reflectivity. Second, our self-conception guides us - or even forces us - to act based on that conception in order to maintain a unified feeling of identity.

\section{CONCLUDING REMARKS}

We do need to reason in multicultural society but we do it for the sake of cultural understanding, not universal consensus. Culture itself is a diacritical rather than a substantive concept. In Fredic Jameson words, "Culture is not a 'substance' or a phenomenon in its own right, it is an objective mirage that arises out of the relationship between at least two groups, no group 'has' a culture all by itself: culture is nimbus perceived by one group when it comes into contact with and observes another one" (Bennet 1998: 2).

Cultural understanding is needed when multicultural society transforms itself from sociological division to political contestation. Contestation might breed hatred and violence when reason is absent. In such a situation, reason could be blinded by stereotypes, prejudices, or beliefs. This is the problem of divided society where universal assent is hardly possible. Habermas' model of rationality pursues universal assent on a negotiable conflict over interests. A deeply divided society, however, is torn apart by zero-sum conflicts over fundamental values. Conflicts between the fundamental values of liberty and sanctity of life in the abortion issue cannot be easily negotiated and agreed.

There are conflicts where cultural understanding, and not consensual agreement, could play an important role. There two cases, one local and the other international, which can be conceived as exemplars of the success and failure of cultural understanding. First, the success story of Aceh. Indonesian- 
Aceh conflict was a good example of sustainable conflict coloured by deep seated prejudices and stereotypes. There was an absence of enforceable ethical commitment that can enhance the possibility of peace. On one hand, Aceh conceived Indonesian as Javanese imperialist. On the other hand, Indonesian conceived Aceh as separatist or anti NKRI (Unitary State of Indonesian Republic). Those prejudices had been deeply anchored in both parties collective consciousness that cancelled out every single attempt of reconciliation. In such situation, there was no room whatsoever for universal consensus. What happened during reconciliation process was each party tried to establish a mutual cultural understanding. Indonesian tried to understand Aceh separatism as product of their disappointment about centralization and militarization policy during Soeharto regime. Indonesian understood that once Aceh had committed to reconciliation during Soekarno regime. Their commitment was based upon the status "special autonomy to apply Islamic Sharia" given by Soekarno. This kind of cultural understanding was broken by Soeharto regime for economic reasons. What has been broken by Soeharto regime was re-established by Yudhoyono regime during Helsinski peace negotiation. Memorandum of Understanding signed in Helsinski by Indonesian and Aceh representatives was not a result of universal consensus but cultural understanding.

Second, the failed case of French multicultural policy. The case of French revolved around the insistence of French Muslim women to wear headscarves in school from which they were subsequently suspended on refusing to comply with the regulations. This case reveals the necessity to distinguish between a politics of recognition and one of deliberation. French authority held that secularism is universally accepted by citizens of French. Unfortunately, secularism is truly French particular value derived from particular historical condition. The wearing of headscarves could not be defended in terms of Habermas' occidental rationality, since the issue was about the problematical status of consensus itself. Habermas' occidental rationality could actually be guilty of extreme intolerance against cultural traditional tradition, especially Islamic cultural tradition.

Habermas' occidental rationality could not account discursive resolution through cultural understanding. Discursive resolution could only come about when cultural traditions have first become reflective. Cultural reflectivity is possible when each cultural tradition tries to discursively encounter others. In order to do so, each cultural tradition must not adopt occidental-abstract model of rationality that decontextualizes discursive participant from his or her cultural embeddedness. Instead, each cultural tradition should adopt otherregarding mode of rationality that takes into account others' commitment, perspective, or identity. 


\section{REFERENCES}

Bennet, David. 1998. “Introduction”, in: David Bennet (ed.), Multicultural states; Rethinking differences and identity, p. 2. London: Routledge.

Berlin, Isaiah. 1969. Four essays on liberty. Oxford: Oxford University Press.

Crowder, George. 2002. Liberalism and value pluralism. London: Continuum.

Delanty, Gerard. 1997. "Habermas and occidental rationalism; The politics of identity, social learning, and the cultural limits of moral universalism", Sociology Theory 15(1): 30-59.

Habermas, Jurgen. 1984. The theory of communicative action Vol. 1. Translated by Thomas McCarthy. Boston: Beacon Press.

Habermas, Jurgen. 1999. Moral consciousness and communicative action. Translated by Christian Lenhardt. Cambridge: MIT Press.

Korsgaard, Christine M. 2002. The sources of normativity. New York: Cambridge University Press.

Levine, George et al. 1989. "Speaking for the Humanities", American Council of Learned Societies Occasional Paper No. 7 (45 pp.).

Mulhern, Francis. 2000. Culture/Metaculture. London: Routledge.

Nussbaum, Martha. 2000. Women and human development; The capabilities approach. Cambridge: Cambridge University Press.

Parekh, Bhikhu. 2000. Rethinking multiculturalism; Cultural diversity and political theory. London: Macmillan Press.

Rawls, John. 2001. Justice as fairness; A restatement. Cambridge: Harvard University Press.

Searle, John, 1993. "Rationality and realism; What is at stake?", Daedalus Vol. 122 (4): 55-83.

Taylor, Charles. 1995. Philosophical arguments. Cambridge: Harvard University Press. 